\title{
Study on changes in some physiological parameters due to presence of visitors at the bedside of patients admitted to coronary care unit at Ali-ibn Abi Talib Hospital of Rafsanjan, Iran, in 2013
}

\author{
Hamdami Nejad A, BSc ${ }^{1}$, Gorgi Z, MSc ${ }^{2}$, Hajmalek S, BSc ${ }^{1}$, Salarpoor F, BSc ${ }^{3}$, Madadizadeh S, BSc ${ }^{1}$, \\ Parzivand M, BSc ${ }^{1}$, Sadat Hosseini L, BSc ${ }^{3}$, Sheikh Fathollahi M, $\mathrm{PhD}^{* 4}$ \\ 1. Student of Radiology, Paramedical School, Rafsanjan University of Medical Sciences, Rafsanjan, Iran. 2. MSc of \\ Epidemiology, Medical School, Rafsanjan University of Medical Sciences, Rafsanjan, Iran. 3. Student of Laboratory Science, \\ Paramedical School, Rafsanjan University of Medical Sciences, Rafsanjan, Iran. 4. Assistant Prof., Dept. of Epidemiology and \\ Biostatistics, Medical School, Rafsanjan University of Medical Sciences, Rafsanjan, Iran.
}

Abstract

Received: October 2015, Accepted: December 2015

Background: Hospitalization in the coronary care unit (CCU) is a concern for patients and their companions. Different studies have presented conflicting results about the effect of visitors on physiological parameters of patients. The purpose of this study was to determine changes in physiological parameters (systolic and diastolic blood pressure and heart rate) due to presence of visitors at the bedside of patients admitted to CCU at Ali-ibn Abi Talib Hospital of Rafsanjan, Iran.

Materials and Methods: This was a cross-sectional study carried out on 281 patients hospitalized in the CCU. Patients' systolic and diastolic blood pressure and heart rate were obtained using a heart monitoring device 2 hours before, during, immediately, and 2 hours after the visit and were recorded in checklists by nurses. Data were analyzed using two-way repeated measures ANOVA.

Results: Mean and standard deviation of patients' age was 62.96 \pm 12.16 years (ranged between 29-93 years). Mean changes in systolic and diastolic blood pressure and heart rate of patients in studied time periods was statistically significant $(\mathrm{P}<0.001)$, so that they increased during visit, and then, after 2 hours they returned to primary levels. Women's physiological parameters were higher than men's over all time periods $(\mathrm{P}<0.050)$. Patients' average systolic blood pressure did not differ across age groups $(\mathrm{P}>0.050)$. Average diastolic blood pressure in patients older than 70 years was less than other age groups and average heart rate in patients older than 60 years was higher than younger patients $(\mathrm{P}<0.050)$.

Conclusions: The average of physiological parameters increased during visits, but decreased to primary levels 2 hours after visits. These changes were not considered clinically important.

Keywords: Heart Rate, Blood Pressure, Coronary Care Unit (CCU), Visitors, Iran

\section{Introduction}

Most patients with heart failure consider death as a means to ease the suffering of the disease (1). Cardiovascular disease (CVD) is the leading cause of death in industrialized countries (2). The number of patients with heart failure has been reported 3337 in 100,000 population by the Center for Disease Control in Iran (3). Based on the World Health Organization (WHO) reports, CVD will be the leading cause of death worldwide in 2020 (4). Heart rate and blood pressure are useful indicators of the status of blood flow and cardiovascular systems (5) and their increase has a direct relationship with the individual's death (6). Cardiac patients in the acute phase require intensive care and are hospitalized in the coronary care unit (CCU) (7).

\footnotetext{
Corresponding author: Mahmood Sheikh Fathollahi, Dept. of Epidemiology and Biostatistics, Medical School, Rafsanjan University of Medical Sciences, Rafsanjan, Iran. Email: mamoosh502002@yahoo.com
} 
Hospitalization in the CCU leads to mental distress and stress (8). This is the most important and common reaction and has a very negative impact on the course of the disease and the patient's physical and psychological recovery (9).

Restrictions apply to visitors in the CCU, because the presence of visitors may cause high blood pressure and increased heart rate for the patient (10) and puts the patient at risk of stress (11). The survey conducted by Gonzalez et al., on patients in intensive care units (ICUs), demonstrated that most patients believed that visitors do not cause tension, but on the contrary provide comfort and relaxation for them (12). Cacioppo et al. concluded that not allowing visitors for patients in critical conditions caused instability in the treatment, nervous tension, and lack of appropriate response to the drug (13). Ardalan et al. found that mean heart rate, and systolic and diastolic blood pressure in patients before the presence of visitors was higher than during their presence and during the presence of visitors was higher than after their visit (14). They concluded that visitors had a positive effect on reducing the abovementioned indices towards the normal range (14).

In a study conducted on 266 patients, it was observed that not only did visitors not cause any interference with the cardiovascular dysfunction, but the increased duration of the meetings also reduced the amount of anxiety in patients, thus reducing their cardiovascular complications (15). Brown observed harmful changes in blood pressure and heart rate of cardiac patients during the 10-minute meeting with the patient's family in the CCU (16). However, thus far, no permanent conclusions have been made on the visitors' impact on the physiological parameters of patients (17).

Few studies have been conducted on the impacts of visitors on the status and cardiovascular function of patients in the CCU, which showed the different effects of the presence of visitors on physiological parameters of patients. Furthermore, monitoring the physiological status of cardiac patients hospitalized in the $\mathrm{CCU}$ is of grave importance in the maintaining of their health. Due to this fact and the lack of similar researches in this city, this study aimed to investigate the physiological changes (systolic, diastolic, and heart rate) in patients admitted to the CCU of Ali-ibn Abi Talib Hospital in Rafsanjan, Iran, due to the presence of visitors by their bedside.

\section{Material and Methods}

This was a cross-sectional study and the study population consisted of the cardiac patients hospitalized in the CCU of Ali-ibn Abi Talib Hospital of Rafsanjan in 2013. This research project was proposed at the Biomedical Research Ethics Committee and was approved with the ethics code of IR.RUMS.REC.1394.122.

The exclusion criteria included less than 2 days of hospitalization in the $\mathrm{CCU}$, age of less than 20 years, lack of full consciousness, inability to understand the surrounding environment, smoking, drug and alcohol consumption, kidney disease, and taking birth control pills.

Patients with diseases including myocardial infarction (MI), pulmonary edema, congestive heart failure, pulmonary embolism, and cardiac arrhythmia who were hospitalized in the CCU and had the inclusion criteria were enrolled in the study. Personal consent was obtained from the patients or their relatives. The sample size was estimated as 281 patients based on Abbas Poor et al. study in the CCU and cardiac surgery unit of Mashhad University of Medical Sciences, Iran, (18), using the Cochran formula

$n=\left[\frac{\left(Z_{1-\alpha}+Z_{1-\beta}\right) \times \sigma_{d}}{\delta}\right]^{2} ; \alpha=0.05, \beta=0.20, \sigma_{\mathrm{d}}=$ $13.69 \mathrm{mmHg}$ (standard deviation of patients' systolic blood pressure changes), and $\delta=2$ $\mathrm{mmHg}$ (the least decrease in patients' mean 
systolic blood pressure which is clinically important). Convenient sampling method was used for the selection of participants.

Patients' blood pressure was determined through a semi-invasive methods'; using a pressure cuff on patients' left hand while they were lying down. Through chest leads, the heart rate and electrocardiography (ECG) of the patients were shown.

On the second day of hospitalization, the systolic blood pressure $(\mathrm{mmHg})$, diastolic blood pressure $(\mathrm{mmHg})$, and heart rate (number per minute) at 2 hours before, during, immediately after, and 2 hours after the presence of visitors (relatives, second degree relatives, and acquaintances) were automatically measured by the patient monitoring system (model NOVIN S1800, SAADAT Co., Iran). This data was read and recorded in the checklist by the unit nurse.

The time of 2 hours after visiting was chosen with the assumption that after this duration, the intensity of the patient's emotions have decreased and the patient has returned to a normal state and stability. The reason for choosing 2 hours before the visiting time was to compare the patient's condition with 2 hours after the visit.

Information on age (years) and gender (female, male) of the patients were extracted from their medical records and recorded in the checklist. The information collected on the checklists were analyzed using SPSS software (version 15, SPSS Inc., Chicago, IL, USA). Quantitative measures were reported as mean $\pm \mathrm{SD}$ and qualitative values were reported as number (percentage). To evaluate average physiological changes (blood pressure and heart rate) during the period under review according to patients' age (less than or equal to 50,51 to 60,61 to 70 , and over 70 years) and gender, two-way repeated measures ANOVA was used. All P-values of less than or equal to 0.05 were considered significant.

\section{Results}

Of the 281 patients admitted to the CCU, 131 $(46.6 \%)$ were men and $150(53.4 \%)$ were women. Mean and standard deviation of the patients' age was $62.96 \pm 12.16$ years and they were in the age range of 29 to 93 years. In addition, 32 patients $(11.4 \%)$ were of less than or equal to 50 years of age, 98 (34.9\%) of 51-60 years, 72 patients $(25.6 \%)$ of $61-70$ years, and $79(28.1 \%)$ were over 70 years of age. Table 1 illustrates the distribution of age and gender among patients hospitalized in the CCU. Oneway repeated measures ANOVA showed that physiological changes observed during the study period were statistically significant $(\mathrm{P}<0.001)$. This means that the physiological index increased during the visits, and then, slowly declined. Values obtained 2 hours after the visits did not show significant differences compared to those of 2 hours before the visits (Table 2).

Table 1: Frequency distribution of age according to gender of patients hospitalized in the cardiac care unit of Ali-ibn Abi Talib Hospital in Rafsanjan in $2013(n=281)$

\begin{tabular}{cccc}
\hline & $\begin{array}{c}\text { Women } \\
\text { n }(\boldsymbol{\%})\end{array}$ & $\begin{array}{c}\text { Men } \\
\mathbf{n}(\boldsymbol{\%})\end{array}$ & P-value* $^{*}$ \\
\hline$\leq \mathbf{5 0}$ & $17(11.3)$ & $15(11.5)$ & \\
\hline $\mathbf{5 1 - 6 0}$ & $44(29.3)$ & $54(41.2)$ & 0.074 \\
\hline $\mathbf{6 1 - 7 0}$ & $47(31.3)$ & $25(19.1)$ & \\
\hline$>\mathbf{7 0}$ & $42(28.0)$ & $37(28.2)$ & \\
\hline
\end{tabular}

* Chi-square test 
Table 2: Comparison of changes in physiological indices across time periods studied in patients hospitalized in the cardiac care unit $(n=281)$

\begin{tabular}{lccccc}
\hline & $\begin{array}{c}\text { Time } \\
\text { hours before } \\
\text { the visit }\end{array}$ & During the visit & $\begin{array}{c}\text { Immediately } \\
\text { after the visit }\end{array}$ & $\begin{array}{c}2 \text { hours after the } \\
\text { visit }\end{array}$ & P-value $^{*}$ \\
$\begin{array}{l}\text { Physiologicat } \\
\text { indices }\end{array}$ & $120.37 \pm 21.34$ & $124.97 \pm 23.35$ & $121.07 \pm 20.67$ & $119.58 \pm 21.48$ & $<0.001$ \\
\hline $\begin{array}{l}\text { Systolic blood } \\
\text { pressure (mmHg) }\end{array}$ & $73.12 \pm 14.38$ & $77.39 \pm 16.71$ & $74.69 \pm 14.06$ & $73.72 \pm 16.17$ & $<0.001$ \\
\hline $\begin{array}{l}\text { Diastolic blood } \\
\text { pressure (mmHg) }\end{array}$ & $77.68 \pm 15.86$ & $78.66 \pm 17.48$ & $76.13 \pm 16.17$ & $75.43 \pm 14.01$ & $<0.001$ \\
\hline $\begin{array}{l}\text { Heart rate (number } \\
\text { per minute) }\end{array}$ & & & & & \\
\hline
\end{tabular}

* One-way repeated measures ANOVA, $\mathrm{P}<0.05$ considered as significant changes

Regarding the changes in systolic blood pressure, in the time periods studied, two-way repeated measures ANOVA showed that the effect of gender was significant $(P<0.001)$. During the evaluation period, mean systolic blood pressure was higher in women compared to men. The effect of time was also significant. This meant that significant changes occurred in the mean systolic blood pressure of both genders during the evaluation period. It had increased during the visits, and then, started to decline $(\mathrm{P}<$ $0.001)$. However, the interaction between gender and the time period was not significant $(\mathrm{P}=$ 0.512). This means that the changes in the mean systolic blood pressure in men and women examined during the evaluation period were similar (Table 3).

Table 3: Results of two-way repeated measures ANOVA on the physiological parameters of patients admitted to the cardiac care unit $(n=281)$

\begin{tabular}{|c|c|c|c|c|c|c|c|c|c|c|c|}
\hline Gender & & & Men & & & & omen & & & & \\
\hline $\begin{array}{l}\text { Time } \\
\text { Physiological } \\
\text { indices }\end{array}$ & $\begin{array}{l}2 \text { hours } \\
\text { before } \\
\text { the } \\
\text { visit }\end{array}$ & $\begin{array}{l}\text { During } \\
\text { the } \\
\text { visit }\end{array}$ & $\begin{array}{l}\text { Immediatel } \\
\mathrm{y} \text { after the } \\
\text { visit }\end{array}$ & $\begin{array}{c}2 \\
\text { hours } \\
\text { after } \\
\text { the } \\
\text { visit }\end{array}$ & $\begin{array}{c}2 \\
\text { hours } \\
\text { before } \\
\text { the } \\
\text { visit }\end{array}$ & $\begin{array}{l}\text { During } \\
\text { the } \\
\text { visit }\end{array}$ & $\begin{array}{l}\text { Immediat } \\
\text { ely after } \\
\text { the visit }\end{array}$ & $\begin{array}{c}2 \text { hours } \\
\text { after } \\
\text { the } \\
\text { visit }\end{array}$ & $\begin{array}{l}\text { P-value } \\
\text { of the } \\
\text { gender }\end{array}$ & $\begin{array}{l}\text { P-value } \\
\text { of the } \\
\text { time }\end{array}$ & $\begin{array}{l}\text { P-value of } \\
\text { the } \\
\text { interaction }\end{array}$ \\
\hline $\begin{array}{l}\text { Systolic blood } \\
\text { pressure } \\
(\mathrm{mmHg})\end{array}$ & $\begin{array}{c}113.63 \\
\pm \\
19.67\end{array}$ & $\begin{array}{c}120.30 \\
\pm \\
23.23\end{array}$ & $\begin{array}{c}116.90 \\
\pm \\
19.33\end{array}$ & $\begin{array}{c}113.59 \\
\pm \\
21.03\end{array}$ & $\begin{array}{c}126.25 \\
\pm \\
21.06\end{array}$ & $\begin{array}{c}129.05 \\
\pm \\
22.75\end{array}$ & $\begin{array}{c}124.71 \\
\pm \\
21.16\end{array}$ & $\begin{array}{c}124.82 \\
\pm \\
20.55\end{array}$ & $<0.001$ & 0.011 & 0.512 \\
\hline $\begin{array}{l}\text { Diastolic } \\
\text { blood pressure } \\
(\mathrm{mmHg})\end{array}$ & $\begin{array}{c}71.24 \\
\pm \\
12.58\end{array}$ & $\begin{array}{c}75.09 \\
\pm \\
14.43\end{array}$ & $\begin{array}{c}76.17 \\
\pm \\
14.30\end{array}$ & $\begin{array}{c}71.37 \\
\pm \\
16.20\end{array}$ & $\begin{array}{c}74.75 \\
\pm \\
15.65\end{array}$ & $\begin{array}{c}79.40 \\
\pm \\
18.28\end{array}$ & $\begin{array}{c}73.41 \\
\pm \\
13.76\end{array}$ & $\begin{array}{c}75.78 \\
\pm \\
15.90\end{array}$ & 0.010 & 0.005 & 0.014 \\
\hline $\begin{array}{ll}\begin{array}{l}\text { Heart } \\
\text { (number }\end{array} & \text { per } \\
\text { minute) } & \end{array}$ & $\begin{array}{c}73.33 \\
\pm \\
13.08\end{array}$ & $\begin{array}{c}74.18 \\
\pm \\
15.19\end{array}$ & $\begin{array}{c}71.78 \\
\pm \\
14.03\end{array}$ & $\begin{array}{c}72.43 \\
\pm \\
13.50\end{array}$ & $\begin{array}{c}81.48 \\
\pm \\
17.09\end{array}$ & $\begin{array}{c}82.58 \\
\pm \\
19.07\end{array}$ & $\begin{array}{c}79.93 \\
\pm \\
16.98\end{array}$ & $\begin{array}{c}78.06 \\
\pm \\
13.96\end{array}$ & $<0.001$ & 0.070 & 0.688 \\
\hline
\end{tabular}

$\mathrm{P}<0.05$ considered as significant effect

Regarding the changes in diastolic blood pressure in the time periods studied, results of the analysis showed that the effect of gender was significant $(\mathrm{P}=0.010)$. During the evaluation time periods (with the exception of the time immediately after the visits), mean diastolic 
blood pressure was higher in women compared to men. Furthermore, the effect of time and the interaction between gender and the time period was significant. This means that both genders during the evaluation periods showed significant changes in mean diastolic blood pressure $(\mathrm{P}<$ 0.001). However, the pattern of changes in diastolic blood pressure in men and women were significantly different $(\mathrm{P}=0.014)$. In women, it had increased during the visits and decreased immediately after the visits, and then, increased again. However in men, it had increased until immediately after the visit, and then, decreased (Table 3).

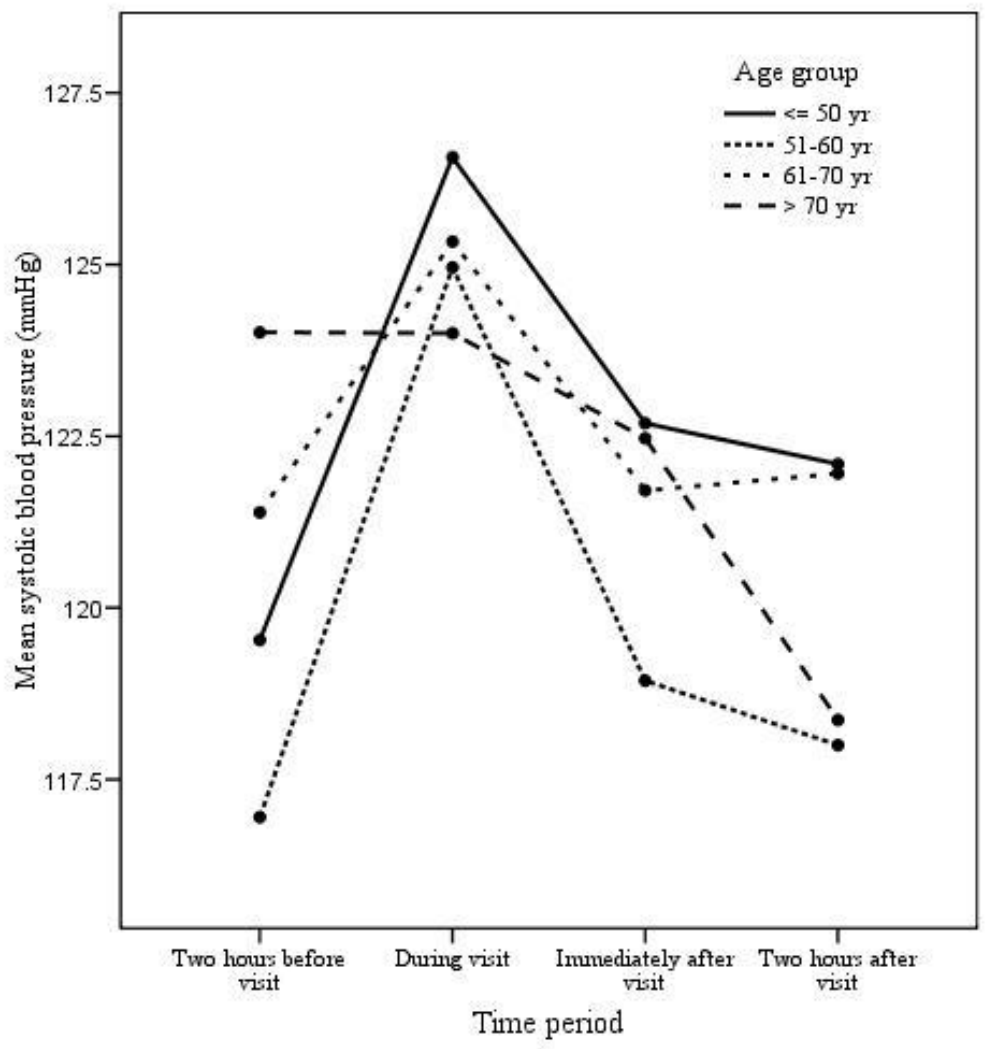

Figure 1: Comparison of changes in systolic blood pressure based on age across time periods studied in patients hospitalized in the cardiac care unit $(n=281)$

In studying the changes in heart rate in the mentioned time periods, the results showed that the effect of gender was significant $(\mathrm{P}<0.001)$. During the evaluation periods, the mean heart rate of women was higher compared to men. The effect of time was also significant $(\mathrm{P}<0.001)$. This means that significant changes were observed in the mean heart rate of both genders during the evaluation periods. However, the interaction of genders and time period was not non-significant $(\mathrm{P}=0.688)$. Thus, changes in mean heart rate during the assessment period were similar in men and women (Table 3).

In reviewing the changes in systolic blood pressure, the effect of age was not statistically significant $(P=0.250)$. This means that there was no statistically significant difference in mean systolic blood pressure in the age groups during the evaluation periods. The effect of time was statistically significant $(\mathrm{P}<0.001)$. This means that significant changes in mean systolic blood pressure were observed in the age groups 
during the evaluation periods; it increased during the visits, and then, began to decline. Nevertheless, the effect of age and time period was not statistically significant $(P=0.865)$. This means that the pattern of changes in systolic blood pressure during the evaluation periods was similar across the age groups (Figure 1).

Regarding the changes in diastolic blood pressure, the effect of age was statistically significant $(\mathrm{P}=0.012)$. Unlike the less than or equal to 50 years age group, in the age group of above 70 years, mean diastolic blood pressure was lower than the other age groups. The effect of time was statistically significant $(\mathrm{P}<0.001)$. In total, significant changes occurred in mean diastolic blood pressure of the patients in the age groups during the evaluation period. The interaction between age and time period was not statistically significant $(\mathrm{P}=0.727)$. This means that the pattern of changes in diastolic blood pressure during the evaluation period was similar across the age groups (Figure 2).

Regarding the changes of heart rate, the effect of age was statistically significant $(\mathrm{P}<0.001)$. Mean heart rate was higher in the age groups above 60 years than the younger age groups. The effect of time was statistically significant $(\mathrm{P}<$ 0.001). This means that in total, significant changes occurred in mean heart rate of the age groups during the evaluation periods. The interaction between age and evaluation periods was not statistically significant $(\mathrm{P}=0.729)$. This means that the pattern of heart rate changes in the time period studied was similar across the age groups (Figure 3).

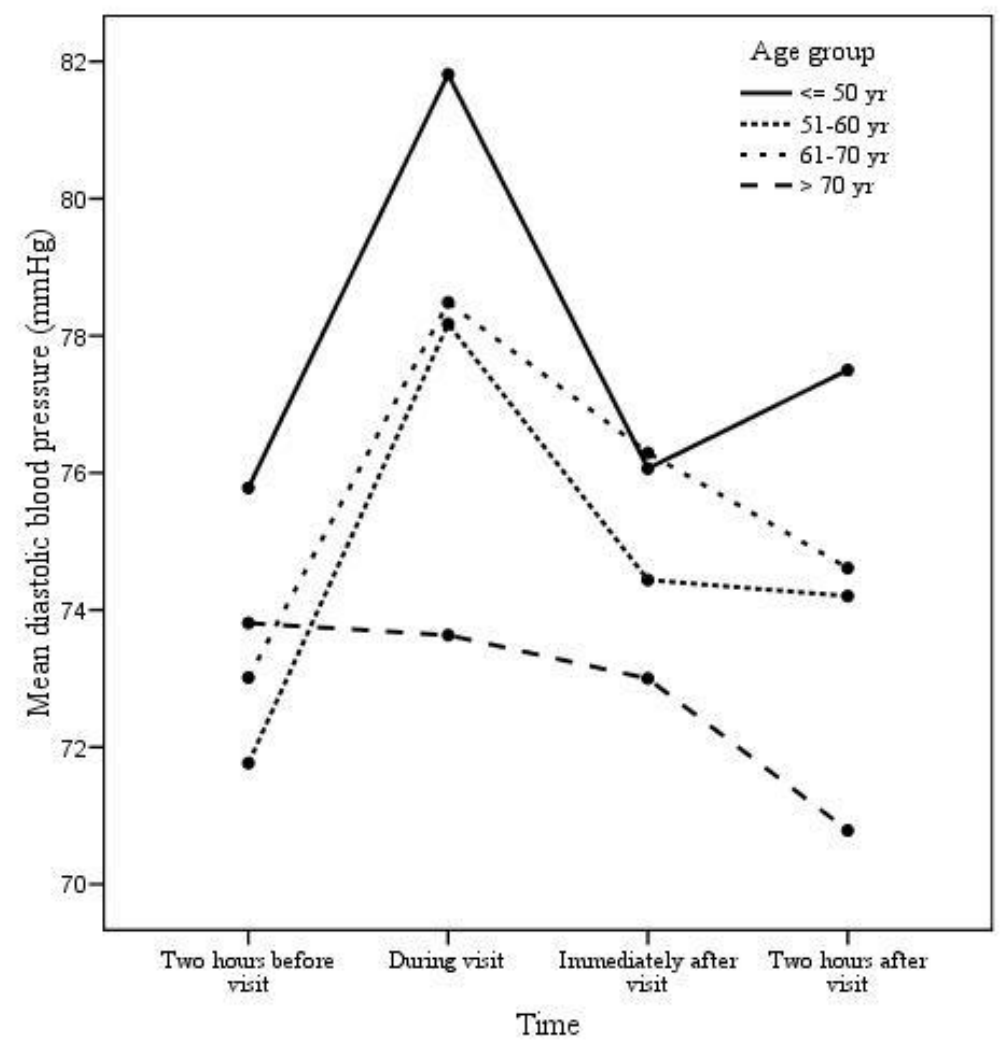

Figure 2: Comparison of changes in diastolic blood pressure based on age across time periods studied in patients hospitalized in the cardiac care unit $(n=281)$ 


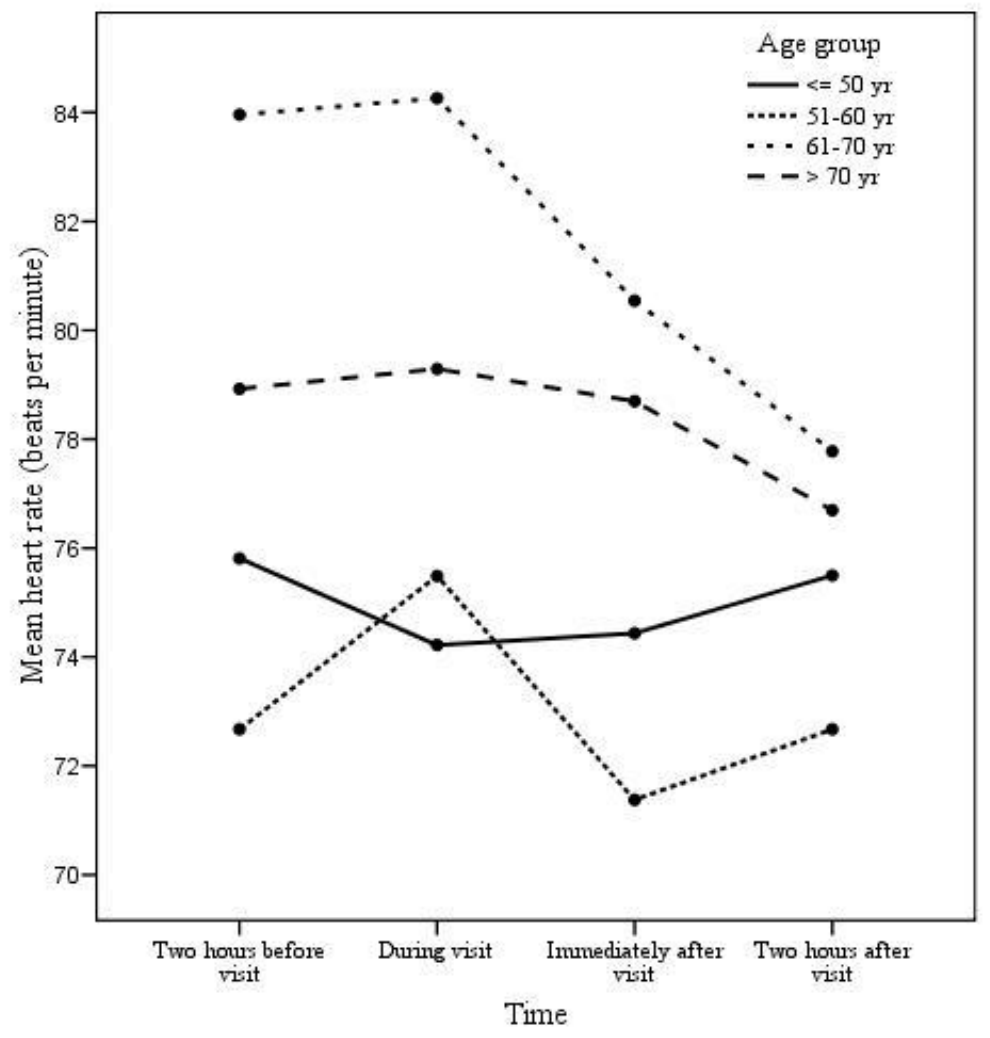

Figure 3: Comparison of changes in heart rate based on age across time periods studied in patients hospitalized in the cardiac care unit $(n=281)$

\section{Discussion}

This study aimed to assess the impact of visitors on systolic blood pressure, diastolic blood pressure, and heart rate of patients admitted to the CCU. The results showed that the physiological indices studied significantly increased during the visits and decreased after the visits. Moreover, they showed no significant difference 2 hours after the visits compared to their initial value in 2 hours before the visits. In this regard, Karami et al. concluded that changes in blood pressure and heart rate before, during, and after the visits were significant (19). They found that the mentioned indicators had increased after the start of the visit, had decreased again after the visits and did not have a statistically significant difference with the amount before the start of the visits. They also found that 30 minutes after the visit, the indicators returned to their original level (19). In a similar study, Ashraf pour concluded that patients' blood pressure and heart rate had increased during the visit and decreased again 30 minutes after the visit, and this difference was statistically significant (20).

In the present study, systolic blood pressure, diastolic blood pressure, and heart rate, in the time period studied, were higher in women compared to men. This may be due to greater stimulation of the nervous system, more anxiety, less consumption of beta-blockers, and less physical activity in women. In this regard, Amirsasan et al. concluded that heart rate in women was higher than men, but systolic and diastolic blood pressure was higher in men, which was not statistically significant (21).

Regarding the study of changes in systolic and diastolic blood pressure and heart rate in all the 
age groups, these indicators showed the same changes. They increased during the visits, and then, decreased. Increase in these indicators may be because of the stimulation of the sympathetic nervous system due to increased stress in the patient during the visit.

In studying the changes in diastolic blood pressure, the effect of age was statistically significant. The mean diastolic blood pressure in the 70 years and above age group was lower than the others. Recent studies have examined the differences in blood pressure among healthy individuals in different age groups; as their age increased, their blood pressure also increased (22). The reduction in diastolic blood pressure observed in this study may be due to the hardening of the arterial walls with aging, which consequently leads to a drop in diastolic blood pressure. This effect is called the Windkessel effect. Mean heart rate was higher in over 60 years age groups than the younger age groups. In patients hospitalized in the CCU because of a heart condition, the heart rate increases.

Lolaty et al. in a similar study found a decrease in the heart rate in the normal range in patients during visits; this has a positive result in terms of patients' improvement. This indicator returned to its initial value after the visit (23). The results of the study by Rahmani et al. showed that the patient's heart rate had declined at the time of the visit compared with the time before the visit, although this reduction was not statistically significant (24). Karami et al. found that the mean heart rate difference of the patients during the visits had significantly increased, while 10 and 30 minutes after the visits it had significantly decreased and this decrease was statistically significant (19). The differences observed in the results may be due to the training of the visitors regarding the correct behavior while visiting the patients. It is suggested that further studies be conducted to measure the effect of trained visitors on physiological parameters. The education should be in line with correct behavior of the visitors in order to reduce the patients' stress during the visits.

The results showed that the 30 minutes time of visiting the patients did not have long-term adverse effects on the physiological parameters of patients admitted to the CCU. Thus, it is suggested to the CCU officials not to limit the visiting hours. Despite the cross-sectional increase in the indicators caused by the visitors, it does not have a certain and long-term effect on the patients.

The limitations of this study include failure to review the conditions of the patients in terms of the type of CVD. Through the consideration of this factor, the changes in these physiological indices will be obtained separately based on the illness of each patient. Therefore, it is recommended that this factor be taken into consideration in future studies.

\section{Conclusion}

The mean systolic blood pressure, diastolic blood pressure, and heart rate of patients admitted to the CCU during the visits showed an increase in the normal range. It had a small decrease immediately after the visits and it returned to the original value 2 hours after the visit. The mean of all the indicators were higher in women than men. Changes in systolic blood pressure were similar in the different age groups, but differences were observed in the other indicators. Stress and anxiety were the main factors known to reduce the health of the cardiac patient, and the results showed that the presence of visitors did not have a negative effect on the above indicators. Therefore, there was no evidence of the visits causing tension and no reason to limit the visiting time.

\section{Acknowledgments}

Our sincere appreciation goes to the Research Deputy of Rafsanjan University of Medical 
Sciences for the funding of this study, and the professors, nurses of the CCU of Ali-ibn Abi Talib Hospital, and all the patients who participated in this study.

Conflict of interest: None declared.

\section{References}

1. Stromberg A, Jaarsma T. Thoughts about death and perceived health status in elderly patients with heart failure. Eur J Heart Fail 2008; 10(6):608-13.

2. Roger VL, Go AS, Lloyd-Jones DM, Benjamin EJ, Berry JD, Borden WB, et al. Heart disease and stroke statistics-2012 update: A report from The American Heart Association. Circulation 2012; 125(1):e2-e220.

3. Rahnavard Z, Zou-alfaghari M, Kazemnejad A, Hatamipour Kh. An investigation of quality of life and factors affecting it in the patients with congestive heart failure. Journal of Hayat 2006; 12(1):77-86.

4. Peltonen M, Lundberg V, Huhtasaari F, Asplund K. Marked improvement in survival after acute myocardial infarction in middle-aged men but not in women. The Northern Sweden MONICA study 1985-94. J Intern Med 2000; 247(5):579-87.

5. Nagaya T, Yoshida H, Takahashi H, Kawai M. Resting heart rate and blood pressure, independent of each other, proportionally raise the risk for type-2 diabetes mellitus. Int $\mathbf{J}$ Epidemiol 2010; 39(1):215-22.

6. Collier SR. Sex differences in the effects of aerobic and anaerobic exercise on blood pressure and arterial stiffness. Gend Med 2008; 5(2):11523.

7. Lukkarinen $\mathrm{H}$, Hentinen $\mathrm{M}$. Treatments of coronary artery disease improve quality of life in the long term. Nurs Res 2006; 55(1):26-33.

8. Quinio P, Savry C, Deghelt A, Guilloux M, Catineau J, Tinténiac A. A multicenter survey of visiting policies in French intensive care units. Intensive Care Med 2002; 28(10):1389-94.

9. Huffman JC, Smith FA, Blais MA, Januzzi JL, Fricchione GL. Anxiety, independent of depressive symptoms, is associated with inhospital cardiac complications after acute myocardial infarction. J Psychosom Res 2008; 65(6):557-63.
10. Ghiyasvandian Sh, Abbaszadeh A, Ghujazadeh M, Sheikhalipoor Z. The effect of open visiting on intensive care nurses' beliefs. Research Journal of Biological Sciences 2009; 4(1):64-70.

11. Lee MD, Friedenberg AS, Mukpo DH, Conray K, Palmisciano A, Levy MM. Visiting hours policies in New England intensive care units: strategies for improvement. Crit Care Med 2007; 35(2):497-501.

12. Gonzalez CE, Carroll DL, Elliott JS, Fitzgerald PA, Vallent HJ. Visiting preferences of patients in the intensive care unit and in a complex care medical unit. Am J Crit Care 2004; 13(3):194-8.

13. Cacioppo JT, Hawkley LC. Social isolation and health, with an emphasis on underlying mechanisms. Perspect Biol Med 2003; 46(3 Suppl):S39-52.

14. Ardalan M, Manaseki P, Ghazizadeh A. Effects of visitors on the bedside of patients admitted to coronary care unit on cardiovascular indicators changes at Tohid Hospital Sannandaj. Journal of Kurdistan Medical University 1998; 8(2):18-23.

15. Fumagalli S, Boncinelli L, Nostro AL, Valoti P, Baldereschi G, Bari MD, et al. Reduced cardiocirculatory complications with unrestrictive visiting policy in an intensive care unit; results from a pilot randomized trial. J Am Heart Assoc 2006; 113(7):946-52.

16. Brown AJ. Effect of family visits on the blood pressure and heart rate of patients in the Coronary-care unit. Heart Lung 1976; 5(2):291-6.

17. Livesay S, Gilliam A, Mokracek M, Sebastian S, Hickey JV. Nurses' perceptions of open visiting hours in neuroscience intensive care unit. J Nurs Care Qual 2004; 20(2):182-9.

18. Abbas Poor S, Hooshmand P. Patient's perception of visiting, severity of illness and related cardiovascular responses in critical care units in Mashhad Medical Sciences. Journal of Birjand University of Medical Sciences 1999; 6(1-2):56-61.

19. Kamrani F, Seiedjavadi M, Abedsaeedi Z, Alavimajd H, Hosseinian E. Physiologic indices of patients before, during and after visit in coronary care unit at Imam Khomeini hospital in Ardabil. Journal of Nursing Of Midwifery 2010; 20(70):18-22.

20. Ashraf pour M. Cardiovascular responses to visiting in coronary care unit patients in Tehran hospitals. [MSc Thesis]. Tehran: Tehran University of Medical Science; 1995.

21. Amirsasan R, Sani S. The effect of age and gender on blood pressure recovery after exhaustive exercise in non-athletic healthy males 
and females. Sport Biosciences 2012; 4(12):5776.

22. Azizi A, Abasi MR, Abdoli GH. The prevalence of hypertension and its association with age, sex and BMI in a population being educated using community-based medicine in Kermanshah: 2003. Iranian Journal of Endocrinology \& Metabolism 2008; 10(4):323-9.

23. Lolaty HA, Bagheri-Nesami M, Shorofi SA, Golzarodi T, Charati JY. The effects of family- friend visits on anxiety, physiological indices and well-being of MI patients admitted to a coronary care unit. Complement Ther Clin Pract 2014; 20(3):147-51.

24. Rahmani R, Ahmadian Yazdi R, Motahedian E, Rahimi A. To assess the effect of planed meeting on the physiologic indicators of the patients who suffer from Acute Coronary Syndrome. Iranian Journal of Critical Care Nursing 2013; 6(1): 5764. 